\title{
Acquisition and regeneration of Spinacia turkestanica Iljin and $S$. tetrandra Steven ex M. Bieb. to improve a spinach gene bank collection
}

\author{
Rob van Treuren • Liesbeth de Groot • Hikmat Hisoriev • Furkat Khassanov • \\ Vahid Farzaliyev - Gayane Melyan • Ivan Gabrielyan · Loek van Soest • \\ Corrie Tulmans - David Courand · Jan de Visser - Ryo Kimura • \\ Jordi C. Boshoven - Takuya Kanda • Ruud Goossens • Manja Verhoef • \\ Jan Dijkstra $\cdot$ Chris Kik
}

Received: 11 December 2018/ Accepted: 5 June 2019/Published online: 13 June 2019

(C) The Author(s) 2019

\begin{abstract}
Spinach (Spinacia oleracea L.) is a highly nutritious leafy vegetable and an economically important food crop. The wild species $S$. turkestanica Iljin and S. tetrandra Steven ex M. Bieb. are inter-fertile with cultivated spinach and constitute important sources of novel characters to improve spinach varieties, such as for their resistance to pests and diseases. Despite their relevance in plant breeding, $S$. turkestanica and $S$. tetrandra are poorly represented in
\end{abstract}

Loek van Soest: Formerly affiliated to Centre for Genetic Resources, the Netherlands.

R. van Treuren $(\bowtie) \cdot$ L. de Groot · C. Kik

Centre for Genetic Resources, the Netherlands, Wageningen Plant Research, P.O. Box 16, 6700 AA Wageningen, The Netherlands

e-mail: robbert.vantreuren@wur.nl

H. Hisoriev

Institute of Botany, Tajik Academy of Sciences,

Dushanbe, Tajikistan

F. Khassanov

Institute of Botany, Uzbek Academy of Sciences,

Tashkent, Uzbekistan

V. Farzaliyev

Central Botanical Garden of NAS of Azerbaijan, Baku,

Azerbaijan

G. Melyan

Scientific Center of Agrobiotechnology, Armenian

National Agrarian University, 1 Isi-Le-Mulino Street

1101, Etchmiadzin, Armenia genetic resources collections. Among the reasons for these collection gaps are the difficulties in propagating these species ex situ. Here we report on the results of collecting expeditions for S. turkestanica in Central Asia and for S. tetrandra in the Trans-Caucasus, which were organized by the Dutch gene bank in collaboration with several breeding companies. Furthermore, we also present efficient protocols for the ex situ regeneration of these species. These protocols were used to successfully regenerate $66 S$. turkestanica and 36 S. tetrandra samples from the collecting

\author{
I. Gabrielyan \\ Department of Higher Plant Taxonomy, Institute of \\ Botany of NAS RA, Str. Acharyan 1, 0063 Yerevan, \\ Armenia \\ L. van Soest \\ CGN, Bennekom, The Netherlands \\ C. Tulmans \\ Nunhems Netherlands B.V., Napoleonsweg 152, \\ 6083 AB Nunhem, The Netherlands \\ D. Courand \\ Syngenta Seeds B.V., Westeinde 62, 1601 BK Enkhuizen, \\ The Netherlands \\ J. de Visser \\ Pop Vriend Seeds B.V., Middenweg 52, 1619 BN Andijk, \\ The Netherlands
}


expeditions. These new accessions fill up important collection gaps in ex situ conserved genetic resources of spinach and can be used for exploitation in crop improvement.

Keywords Accession maintenance $\cdot$ Collection development · Crop wild relatives · Ethnobotany · Ex situ conservation $\cdot$ Spinach

\section{Introduction}

Cultivated spinach (Spinacia oleracea L.) is a highly nutritious leafy vegetable because of its richness in various vitamins and minerals (Morelock and Correll 2008). Apart from its relevance to the human diet, spinach is also an economically important food crop. According to the Food and Agriculture Organization of the United Nations, 26.7 million tonnes of spinach were harvested world-wide in 2016 from an area of 0.92 million hectares (FAOSTAT 2018).

In addition to characters related to yield, growth and appearance, resistances against pests and diseases are by far the most important targets for breeding new spinach varieties. Pests and diseases that are common in spinach include leaf miners (Liriomyza Mik spp.), leaf spot (e.g. Stemphylium botryosum Wallr.), white rust (Albugo occidentalis G.W. Wilson), Fusarium

\section{R. Kimura}

Sakata Seed Corporation, 358 Uchikoshi, Sodegaura, Chiba 299-0217, Japan

\section{J. C. Boshoven}

Bejo Zaden B.V., Trambaan 1, 1749 CZ Warmenhuizen, The Netherlands

\section{T. Kanda}

Takii, Naganuma Plant Breeding Station and Experiment Station, Naganuma, Yubari, Hokkaido 069-1302, Japan

R. Goossens

Bayer Netherlands - Crop Science, Wageningse Afweg 31, 6702 PD Wageningen, The Netherlands

M. Verhoef

Rijk Zwaan Breeding B.V., Burgemeester Crezéelaan 40, 2678 ZG De Lier, The Netherlands

J. Dijkstra

Enza Zaden Research and Development B.V., Haling 1/E, 1602 DB Enkhuizen, The Netherlands wilt (Fusarium oxysporum emend. Snyder \& Hansen f.sp. spinaciae), but in particular downy mildew (Peronospora farinosa (Fr.) Fr. f.sp. spinaciae or Peronospora effusa (Greville) Rabenhorst) which is nowadays the most threatening disease to spinach cultivation. Particularly worrisome is the increasing rate at which the pathogen is breaking disease resistance in spinach production fields (Morelock and Correll 2008; Andersen and Torp 2011). In April 2018, the International Working Group on Peronospora (IWGP) denominated Pfs: 17, the latest race of spinach downy mildew (Plantum 2018).

Spinach is considered to have been domesticated in former Persia (Iran), from which the crop spread to China, North Africa and Europe, and in more recent times to North America (Sneep 1982). This domestication history was recently confirmed by transcriptome sequencing of 120 Spinacia accessions. Furthermore, the transcriptome data suggested that the wild species Spinacia turkestanica Iljin is likely the direct progenitor of cultivated spinach and that only a weak bottleneck occurred during crop domestication (Xu et al. 2017). Also the wild Spinacia tetrandra Steven ex M. Bieb. is generally found interfertile with $S$. oleracea, alhough pollen viability can be low (Fujito et al. 2015), and hence these three species are considered to constitute the spinach primary gene pool (Fig. 1). S. turkestanica is mainly distributed in Central Asia and S. tetrandra in the Trans-Caucasus, both areas neighbouring the native region of cultivated spinach (Uotila 1997).

Due to the arms race with new races of spinach downy mildew, plant breeders are continuously looking for new resistance sources against this fastevolving pathogen. Because plant breeders are not always able to find the required traits in the cultivated gene pool, the importance of wild species as a source of novel diversity for the improvement of spinach varieties has strongly increased (Handke et al. 2000; Andersen and Torp 2011). However, access to crop wild relatives in their natural habitat is usually complicated and their representation in genetic resources collections is often limited. Examination of wild relatives associated with 63 crops showed the absence of 313 taxa (29\%) in germplasm collections, while 257 (24\%) were represented with less than 10 specimens (Castañeda-Álvarez et al. 2016). An inventory of spinach genetic resources conserved ex situ in 2010 revealed 2017 accessions from a total of 25 
S. oleracea
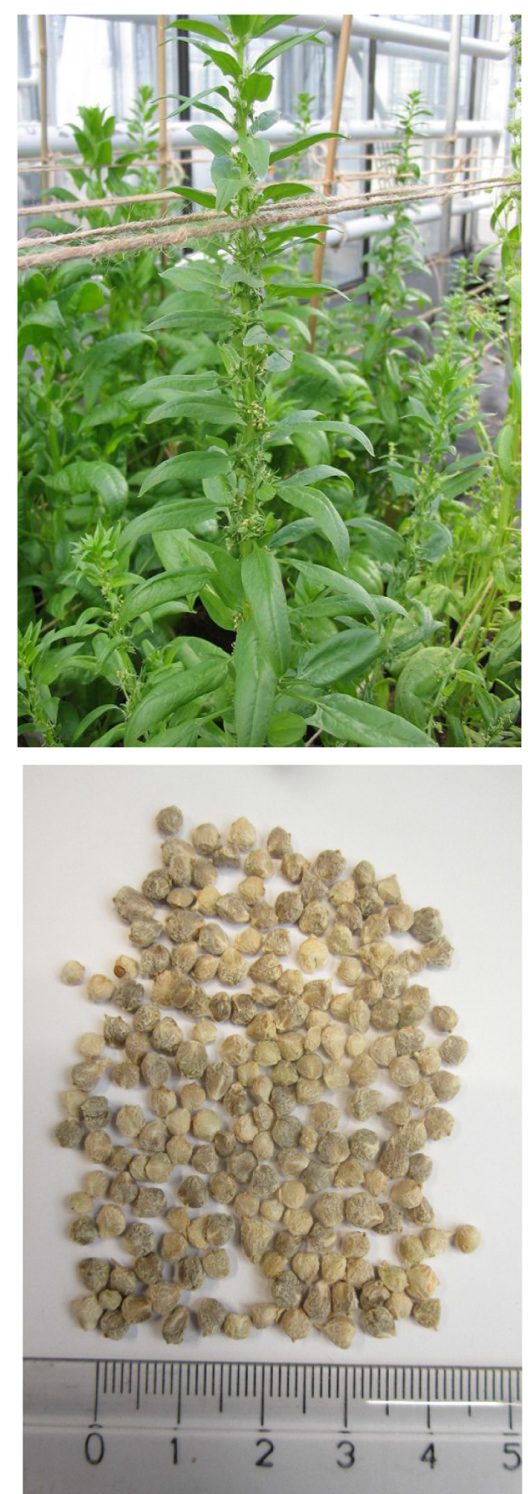

\section{S. turkestanica}
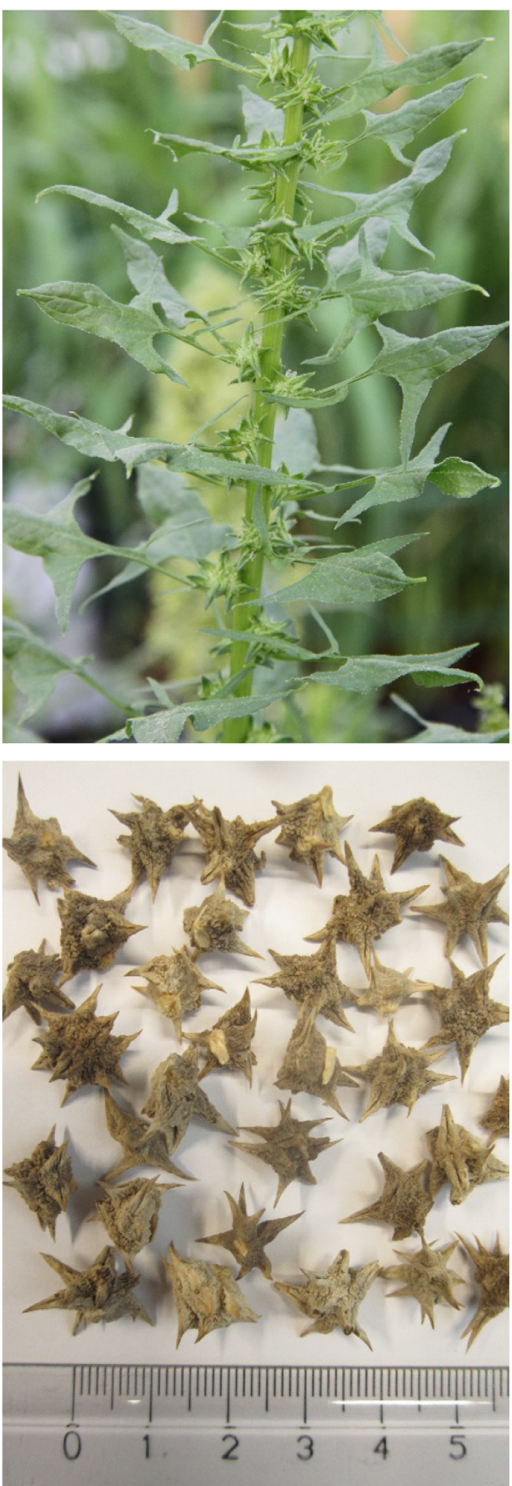

\section{S. tetrandra}
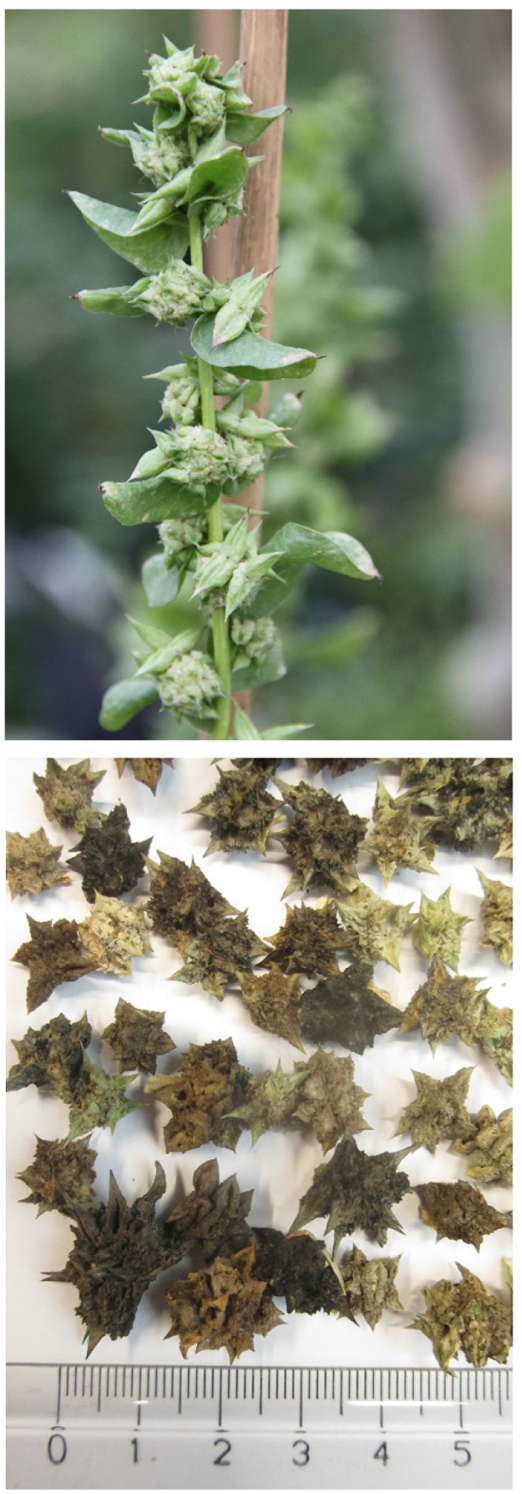

Fig. 1 Plant and seed characteristics of the species that constitute the spinach primary genepool

collections, comprising only 14 accessions of $S$. turkestanica and 12 of $S$. tetrandra (Van Treuren et al. 2012). Most likely the number of unique $S$. turkestanica and $S$. tetrandra accessions are even lower as duplication of germplasm samples has been common practice by gene banks (e.g. Van Hintum 2000). Reasons for the under-representation of crop wild relatives in genetic resources collections may include the high costs involved for an expedition to remote areas and the more stricter legislation regarding access to genetic resources (EU 2018). Moreover, the maintenance of wild species under ex situ conditions may be laborious and may require specific expertise from curators to accomplish germination, flowering and seed production. Here we report on the improvement of the spinach collection of the Centre for Genetic Resources, The Netherlands (CGN) through the sampling of $S$. turkestanica and $S$. tetrandra from their natural distribution area. Furthermore, we present protocols for the successful 
regeneration of these wild populations under ex situ conditions.

\section{Materials and methods}

Germplasm acquisition

Collecting expeditions were carried out for $S$. turkestanica and $S$. tetrandra as a gap analysis performed in 2007 showed that the diversity of these species was poorly represented at that time in ex situ collections world-wide. Moreover, a strong interest for novel genetic resources was expressed by the spinach breeding sector, of which eight and nine companies affiliated to Plantum-NL supported and co-funded the $S$. turkestanica and S. tetrandra expedition, respectively. The collecting missions were carried out in cooperation with local experts.

S. turkestanica was collected in 2008 in Tajikistan from May 28 to June 14 and in Uzbekistan from June 14 to June 28 (Kik 2008). A total distance of roughly $5000 \mathrm{~km}$ was travelled within an area of approximately $100,000 \mathrm{~km}^{2}$. In Tajikistan the city of Dushanbe was used as an operating base for most collecting activities that concentrated on the Southwest part of the country. Other regions were not visited because absence or only low abundance of $S$. turkestanica in 2008 was reported by local experts. A larger geographic area was explored in Uzbekistan, focussing on the Southeast part of the country.

The collecting mission for $S$. tetrandra was preceded by a pre-expedition in 2010 in which potential collecting sites were inventoried by the local experts. S. tetrandra was collected in 2011 in Azerbaijan from May 28 to June 14 and in Armenia from June 24 to July 1 (Kik et al. 2011). Collecting activities were mainly performed at both sides of the lesser Caucasus mountains, separating Azerbaijan in the North from Armenia and the Azerbaijani province of Nakhichevan in the South. Around $4000 \mathrm{~km}$ was travelled within an area of approximately $60,000 \mathrm{~km}^{2}$.

Passport data were documented on collecting forms that largely followed the FAO/Bioversity multi-crop passport descriptor list (Alercia et al. 2015). Geographical data of the collecting sites were registered by GPS (Garmin, e Trex series Venture HC) with an inaccuracy of 1-5 $\mathrm{m}$ and most locations were photodocumented. At each location an area of 0.1-2 ha was examined prior to sampling. After a few days the samples were partially cleaned and transferred to linen bags for transportation. Upon arrival at CGN the samples were placed in a conditioned storage room $\left(15{ }^{\circ} \mathrm{C}, 15 \%\right.$ relative humidity) awaiting further seed processing. Further information about the expeditions can be found on the webpage ' $\mathrm{CGN}$ collecting missions' on the website of CGN (www.cgn.wur.nl).

To provide a legal basis for the collecting expeditions, the competent national authority on access and benefit sharing of each of the target countries was contacted to fulfil requirements regarding Prior Informed Consent (PIC) and Mutually Agreed Terms (MAT). A Memorandum of Understanding (MOU) was signed between CGN and each of the competent national authorities. This MOU adopted the Standard Material Transfer Agreement (SMTA) of the International Treaty for Plant Genetic Resources for Food and Agriculture (IT-PGRFA) as a basis for the distribution of collected germplasm (FAO 2018).

Ex situ regeneration

A few S. turkestanica samples with large seed quantities were used in a pilot study by CGN and each of the eight involved breeding companies using in-house regeneration procedures. Data on regeneration success were evaluated and an integrated regeneration protocol was developed based on best practises. This protocol was used to regenerate all collected $S$. turkestanica samples within the period 2009-2011. A similar approach was followed by the nine involved breeding companies for the $S$. tetrandra samples that were regenerated between 2013 and 2017.

Regenerated seeds were returned to CGN and then shared among all the involved breeding companies. This seed distribution marked the beginning of an embargo of 3 years, which means that only after this period seed samples of the new accessions are made available by CGN to the general user community. Prior to storage at CGN, the spiny parts of the fruit coat were mechanically removed in order to enable seed packaging under vacuum conditions. This was accomplished by squeezing the fruits between a moving rubber conveyer belt and a metal plate using an inhouse developed apparatus. 


\section{Results}

\section{Collecting expeditions}

For $S$. turkestanica 30 seed samples were collected in Tajikistan and 36 in Uzbekistan (Fig. 2). Collecting sites were mostly several kilometres apart, except for a number of locations in the western part of Tajikistan that were more closer to each other. Particularly rich areas of wild spinach were the Lokhur-Isambay valley in Tajikistan, east of the border between Tajikistan and Uzbekistan, and the Gallyaaral area southwest of the Krebet Nuraiau mountain range in Uzbekistan. The altitude of the collecting sites ranged from 657 to
$1300 \mathrm{~m}$ in Tajikistan and from 413 to $1520 \mathrm{~m}$ in Uzbekistan. Habitats in which S. turkestanica was collected can be characterized as cultivated nonirrigated steppe with a loess soil, where the species typically grows along agricultural fields. These fields are locally known as 'bogara' (in Russian) or 'lalmi' (in Uzbek) fields, on which mostly cereals (mainly wheat and barley) and occasionally flax are cultivated. As farmers cannot afford the use of chemical fertilizers and crop protection chemicals, the density of the crop on those fields is often low, which enables $S$. turkestanica to grow even in between the crop. The number of plants sampled per location varied from five to more than hundred, while the number of seed

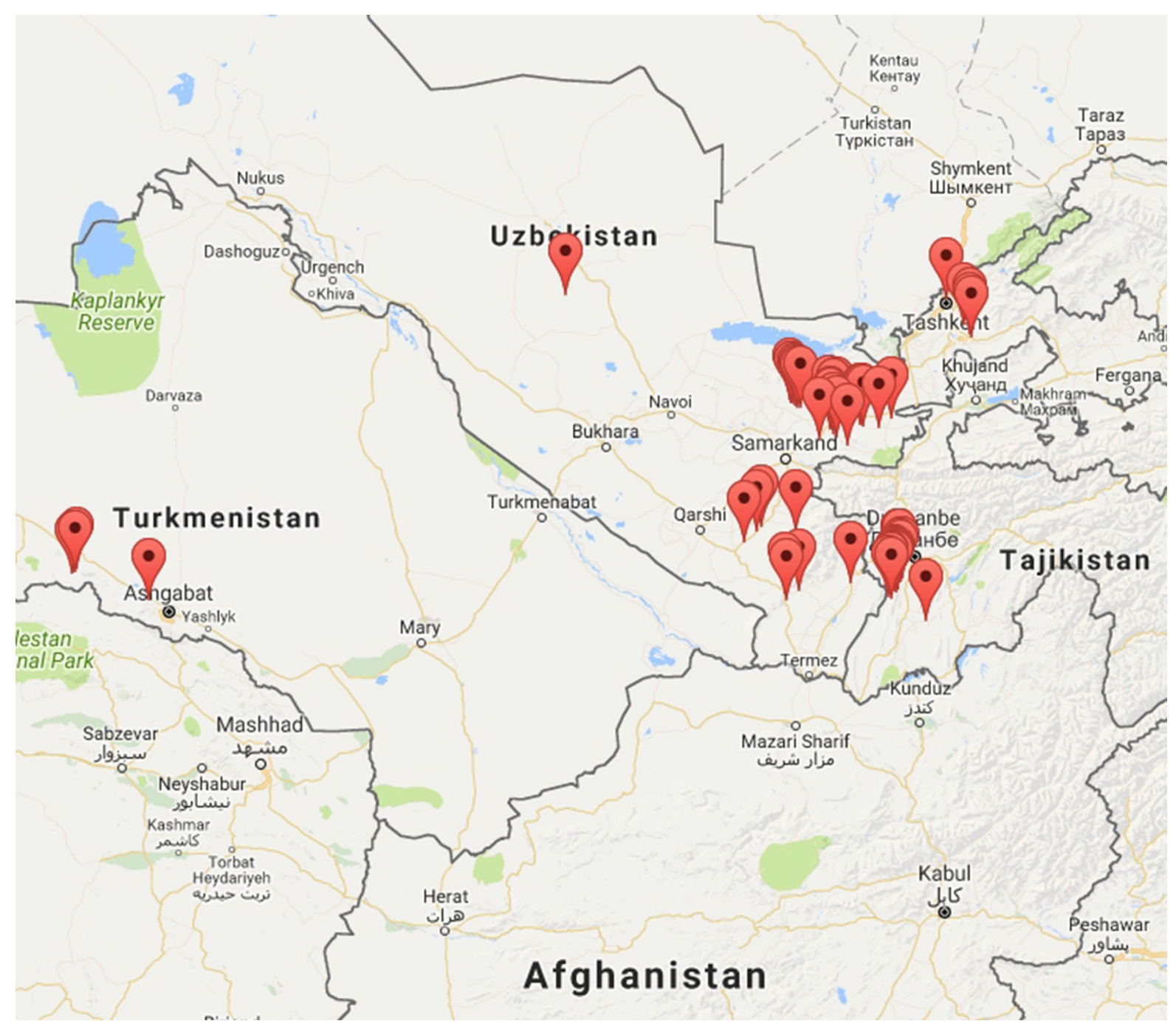

Fig. 2 Origin location of CGN accessions of S. turkestanica in Central Asia, largely collected during a collecting expedition in 2008 
clusters per plant varied from five to fifty. The seed amount collected for $S$. turkestanica varied from 5 to $375 \mathrm{~g}$ per population.

Regarding S. tetrandra 21 populations were sampled in Azerbaijan and 16 in Armenia (Fig. 3). With the exception of a few collecting sites, inter-population distances were mostly in the order of several kilometres. The elevation of the collecting sites ranged from 75 to $1129 \mathrm{~m}$ in Azerbaijan, and were generally higher in Armenia, ranging from 819 to $1174 \mathrm{~m}$. S. tetrandra was collected in a wide variety of habitats, including areas along secondary roads, borders of rivulets, field margins, Hordeum murinum vegetations, cemeteries, along 'bogara' fields and wastelands (nutrient poor, tertiary clay soils). S. tetrandra was often found in salty desert vegetation types cooccurring with Artemisia fragrans, a plant species with silver grey stems and leaves and a typical aroma. S. tetrandra was observed mostly on tertiary clay soils, which are more solid than the loess soils on which $S$. turkestanica was found in Central Asia in 2008. The plants from which seeds were sampled were usually small $(\sim 20 \mathrm{~cm}$ ), except for a few populations that were relatively undisturbed by humans and animals. Seeds were sampled from 25 to 50 plants per collecting site, and the bulked seed yield ranged from 0.1 to $175 \mathrm{~g}$ per population.

During both collecting expeditions male plants were observed only in a single location (Nakhichevan, Azerbaijan). These were juveniles co-occurring with juvenile and mature female plants. No mature male plants were observed at any of the visited locations.

\section{Seed multiplications}

Several in-house protocols were evaluated in a pilot study to develop efficient regeneration protocols for each of the species S. turkestanica and S. tetrandra

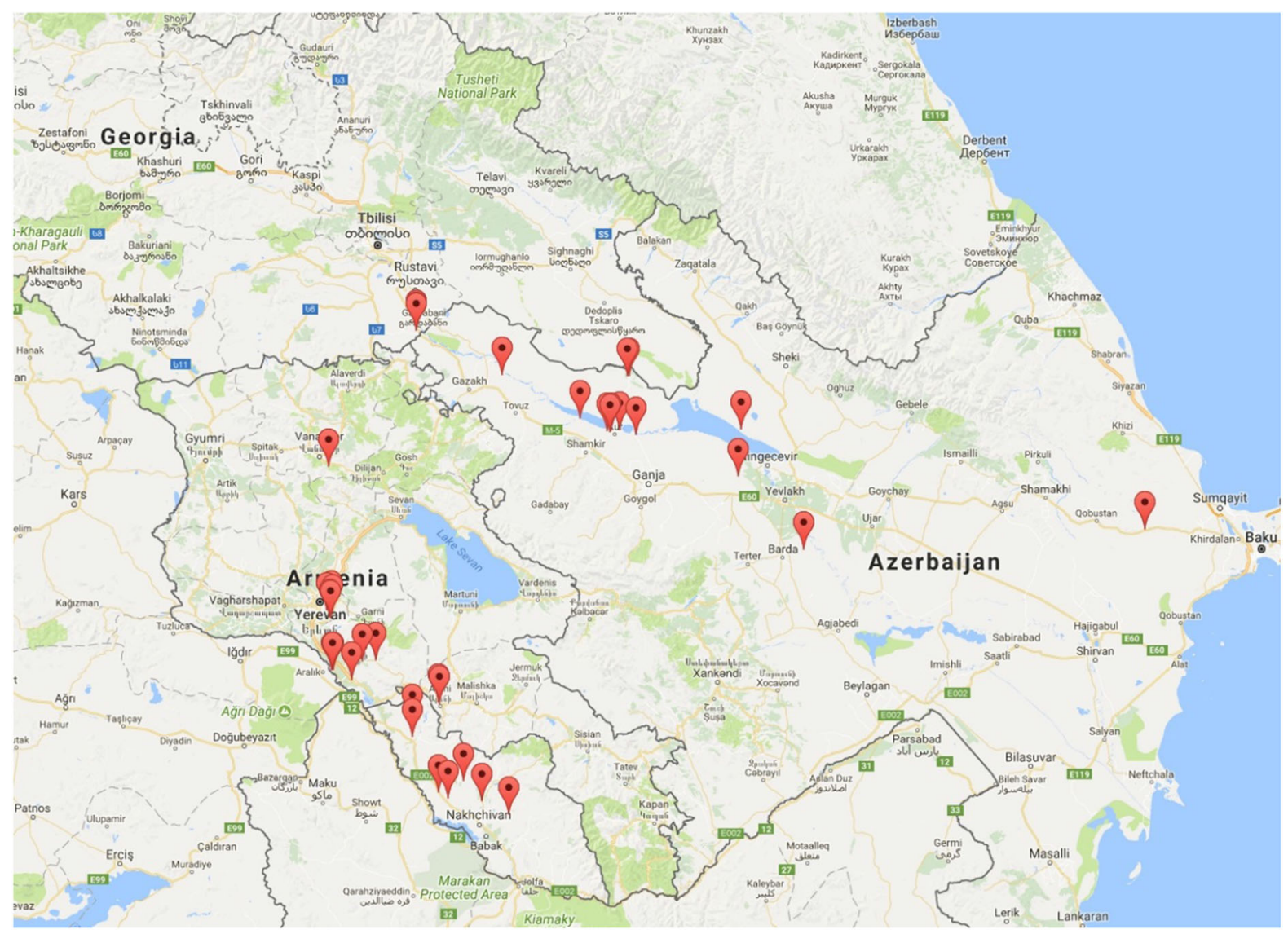

Fig. 3 Origin locations of CGN accessions of S. tetrandra in the Trans-Caucasus, largely collected during a collecting expedition in 2011 
Table 1 Guidelines to regenerate populations of S. turkestanica and S. tetrandra under ex situ conditions

\begin{tabular}{|c|c|}
\hline \multicolumn{2}{|l|}{ S. turkestanica } \\
\hline Pre-treatment of seeds & $\begin{array}{l}\text { Start early January } \\
\text { Breaking of the seed clusters } \\
\text { Rinsing of the seeds in running tap water for } 3 \text { days } \\
\text { Sowing in trays with soil } \\
\text { Cold treatment at } 4{ }^{\circ} \mathrm{C} \text { for } 3-5 \text { days (dark) } \\
\text { Germination in greenhouse for } 2 \text { weeks at } 15-20^{\circ} \mathrm{C} \text {, or under cold/warm } \\
\text { uncontrolled but frost-free conditions (short day) } \\
\text { Repeat cold treatment in case of low germination } \\
\text { Seedlings transplanted in peat pots (short day) }\end{array}$ \\
\hline Cultivation and seed production & $\begin{array}{l}\text { Potting or planting mid to end of March } \\
\text { Cultivation in an isolation room in a greenhouse or outside in a plastic tunnel } \\
\text { Seed harvesting at the end of June }\end{array}$ \\
\hline \multicolumn{2}{|l|}{ S. tetrandra } \\
\hline Pre-treatment of seeds & $\begin{array}{l}\text { Start early January } \\
\text { Rinsing of the seed clusters in } 50{ }^{\circ} \mathrm{C} \text { water for } 30 \mathrm{~min} \\
\text { Cooling down in running tap water for } 10 \mathrm{~min} \\
\text { Surface sterilization in } 4 \% \text { chloride solution for } 24 \mathrm{~h} \\
\text { Rinsing three times in sterile water } \\
\text { Dissection of the seed clusters into separate seeds } \\
\text { Incubation in } 4{ }^{\circ} \mathrm{C} \text { water for } 5 \text { days } \\
\text { In vitro germination at } 15^{\circ} \mathrm{C} \text { or sowing directly in soil } \\
\text { Plant raising under cold/warm uncontrolled but frost-free conditions (short day) }\end{array}$ \\
\hline Cultivation and seed production & $\begin{array}{l}\text { Cultivation in an isolation room in a greenhouse or outside in a plastic tunnel } \\
\text { Seed harvesting at the end of June }\end{array}$ \\
\hline
\end{tabular}

${ }^{\mathrm{a}} \mathrm{Can}$ also be performed prior to the dissection of the seed clusters

(Table 1). Fruits of both species generally consist of 4-5 seeds and pre-treatment of the seed clusters is the crucial step in the regeneration process. The seed clusters of $S$. turkestanica are first broken without damaging the seeds, e.g. using a pliers, followed by rinsing in tap water for 3 days. Sowing is performed in trays that are maintained at $4{ }^{\circ} \mathrm{C}$ for several days to reduce dormancy. The cold treatment is repeated in case of insufficient germination. The seed clusters of S. tetrandra are first subjected to a series of treatments with hot water, cold water and $4 \%$ chloride. The hot water and chloride treatment are applied to kill external bacteria. The chloride treatment is also intended to soften the fruit coat, which facilitates the dissection of the clusters. Seed clusters can be dissected into separate seeds using a binocular, scalpel and tweezers. While freeing the seed from the fruit coat, care should be taken not to damage the seed coat, nor the root of the embryo. Plants of both species should be raised under short-day ( $8-9$ h light) conditions in order to prevent early bolting.

As Spinacia species are dioecious, attention should be paid to the number of male and female plants, which ideally are more or less equal when regenerating populations. Populations are regenerated in isolation to avoid inter-population gene flow. Because Spinacia species are wind-pollinated, sufficient air circulation should occur during flowering. Regenerations are usually carried out with 100-200 plants, resulting in a seed harvest of 400-900 $\mathrm{g}$ for $S$. turkestanica and 300-600 g for S. tetrandra.

Apart from a single $S$. tetrandra sample, consisting of only a few low-quality seeds, all expedition materials were successfully regenerated and introduced in the CGN collection. In addition, nine accessions of $S$. turkestanica and three of $S$. tetrandra 
were obtained from other sources (Table 2). All accessions of $S$. turkestanica and about half of those of $S$. tetrandra are available for distribution. The availability of the entire set of $S$. tetrandra accessions is planned for the end of 2020 .

\section{Discussion}

Ethnobotanical aspects

In each of the four countries visited during the two expeditions, commercial cultivation of spinach was found to be rare. Nevertheless, low-scale commercial cultivation in Uzbekistan and Azerbaijan was reported by local seed sellers. During the two collecting expeditions a total of 11 landraces of S. oleracea were obtained from bazars or home gardens. Also these landraces were regenerated and included in the collection of CGN.

Wild spinach in the expedition areas is known to be collected from their natural habitat during springtime and to be sold at local markets. This was reported for $S$. turkestanica from the Lokhur-Isambay valley in Tajikistan and for S. tetrandra from the area around Baku in Azerbaijan. Wild spinach is the first available vegetable for consumption by local people after wintertime. This collecting activity may have underlied the difficulties to obtain seeds samples of $S$. tetrandra in the area around Baku. However, in general grazing of juvenile plants by sheep and goats is more threatening to wild spinach populations.

Fresh leafs of cultivated and wild spinach are used as a spice in food, e.g. as an ingredient in rice, yoghurt or soup. Outside the harvesting season, dried spinach leafs are only used in soups. A water extract from spinach seeds, obtained after 5 min of boiling in water, is used as a medicine against kidney problems.

Genetic resources management

Optimal access to genetic resources is crucial to the improvement of our crops. Wild relatives continue to play an important role in plant breeding programmes, especially in responding to rapidly evolving pathogens that require recurring and targeted introduction of new alleles into cultivated gene pools (Hajjar and Hodgkin 2007; Van de Wouw et al. 2010). However, crop wild relatives are generally poorly represented in gene bank collections (Khoury et al. 2010; Castañeda-Álvarez et al. 2016), while their accessibility in situ is generally complicated. Moreover, the survival of crop wild relatives in situ may be threatened by various factors, including climate change (Jarvis et al. 2008; Van Treuren et al. 2017). Enriching gene bank collections with crop wild relatives will not only provide better access to their diversity in the short term, it will also serve as back-up of variation occurring in the wild when species become seriously endangered in situ (Maxted et al. 2015). Here we reported on the results of collecting expeditions for $S$. turkestanica and $S$. tetrandra, the only two wild species of the spinach primary gene pool. So far their number of gene bank accessions has been rather small, while their natural distribution areas are located in Central Asia and the Trans-Caucasus, respectively, causing restricted accessibility of these genetic resources to users. In the collecting areas wild spinach populations were often found in the margins of agricultural fields. Such populations are potentially threatened when the management of the fields is changed from low-input farming to a system with
Table 2 Origin and availability of accessions of $S$. turkestanica and $S$. tetrandra at $\mathrm{CGN}$

\begin{tabular}{lcclr}
\hline Origin & Available & Available December 2019 & Available December 2020 & Total \\
\hline S. turkestanica & & & & \\
Tajikistan & 30 & & 30 \\
Turkmenistan & 5 & & & 5 \\
Uzbekistan & 38 & & 3 & 2 \\
Unknown & 2 & & 7 & 16 \\
S. tetrandra & & 4 & & 20 \\
Armenia & 9 & 6 & & 3 \\
Azerbaijan & 7 & 3 & & \\
Georgia & 3 & & & \\
\hline
\end{tabular}


irrigation and the use of chemical fertilizers and herbicides. In particular, this applies to $S$. turkestanica that often occurs as an accompanying species along or within arable fields, making the species more vulnerable to human activities compared to $S$. tetrandra. As we are unaware of any local conservation programmes, we consider our collecting expeditions important contributions to the safeguarding of the genetic resources of wild spinach. The importance of proper accessibility was demonstrated by the $S$. turkestanica material collected in 2008. These materials were found to harbour new resistances against the latest spinach downy mildew races at that time and were used in breeding programs, resulting in the introduction of new spinach varieties in 2014-2015. Also the $S$. tetrandra samples collected in 2011 seem to represent promising genetic resources for resistance breeding against downy mildew in spinach.

Several reasons may underlie the underrepresentation of crop wild relatives in gene banks. Firstly, countries have sovereign rights over the genetic resources occurring on their territory, which means that collecting activities without any formal arrangement with the authorities of the country in question will generally be considered an act of biopiracy. Global biodiversity is protected by the Convention on Biological Diversity (CBD), which encourages countries to provide access to their biodiversity, while benefits arising from its use should be shared with the country of origin. The protocol on the concept of access and benefit sharing (ABS) is laid down in the Nagoya protocol (e.g. EU 2018). In addition to these international agreements, countries may demand bilateral arrangements for collecting expeditions. Thus, in order to provide a legal basis to an expedition, the national competent authority on ABS of a country should be contacted to negotiate the terms and conditions under which an expedition can be organized. Ideally, the SMTA of the IT-PGRFA (FAO 2018), such as used for the $S$. turkestanica and $S$. tetrandra collecting expeditions is used as the basis for germplasm exchange. In practice, communication with the national competent authority on ABS is often difficult to establish or the requirements of countries may be unappealing, such as the restriction to use the material only for non-commercial purposes. Thus, ABS issues are seriously jeopardizing proper access to the genetic resources of countries. In the absence of any conservation program in such countries, valuable genetic resources may be lost forever.

In addition to ABS matters, budget issues also play a role in the poor representation of crop wild relatives in gene banks. Crop wild relatives may have their main distribution area in remote regions, which may require substantial budget to fund a collecting expedition. Expeditions may last for several weeks, especially when multiple countries and large areas are visited. Apart from the costs for transportation and subsistence, budget is needed to hire local experts who are indispensable for a successful expedition. Given the limited budget of many gene banks and the fact that maintenance of their collections is the main priority, external financing is generally needed to fund a collecting expedition. The $S$. turkestanica and $S$. tetrandra collecting expeditions would not have been possible without the support of the plant breeding industry.

The representation of crop wild relatives in gene banks also depends on the question whether they can be successfully propagated under ex situ conditions. Wild species may form a nightmare to gene bank curators because of seed dormancy, delayed or absent flowering and failure to produce viable seeds. Therefore, expertise development is often required to successfully regenerate wild plant species. Here we introduced novel protocols for the successful regeneration of S. turkestanica and S. tetrandra. As is true for many wild species, a crucial step in the regeneration is the breaking of the seed dormancy (FinchSavage and Leubner-Metzger 2006). This was accomplished for $S$. turkestanica and $S$. tetrandra by applying rinsing steps, temperature treatments and release of the seeds from the seed clusters. Seed germination typically ranged from 50 to $80 \%$ for $S$. turkestanica and from 20 to $30 \%$ for S. tetrandra. while no germination was observed for untreated seeds. During the regenerations a more or less equal ratio of male and female plants was observed. However, the male plants quickly senesced after pollen release, whereas the female plants remained vital (cf. Sklensky and Davies 2011). These findings may explain the absence of male plants that was observed at nearly all collecting sites during our expeditions.

CGN uses threshold values of $80 \%$ germination for cultivated materials and $60 \%$ for crop wild relatives, which are in line with the quality standards developed 
for gene bank management procedures (FAO 2013). Such standards are difficult to meet for wild spinach, especially in the case of $S$. tetrandra. To avoid unjustified rejection of seed samples with suboptimal germination, the number of healthy, dormant seeds could be included in the viability estimates. This was achieved for $S$. turkestanica by digging up the seed clusters from the soil trays, followed by dissection and inspection using a binocular. In order to avoid the comprehensive and laborious pre-treatment of seeds, germination tests for $S$. tetrandra were simplified by rinsing the seed clusters for 3 days in water at room temperature and for 5 days in water of $4{ }^{\circ} \mathrm{C}$, followed by in vitro germination at $15^{\circ} \mathrm{C}$ and dissection and inspection of non-germinated seeds after 2 weeks.

Acknowledgements The work described in this paper was carried out in the framework of the Programme Genetic Resources (WOT-03) funded by the Dutch Ministry of Agriculture, Nature and Food Quality. We would also like to thank Bayer Netherlands - Crop Science, Bejo Zaden B.V., Enza Zaden Research and Development B.V., Nunhems Netherlands B.V., Pop Vriend Seeds B.V., Rijk Zwaan Breeding B.V., Sakata Seed Corporation, Syngenta Seeds B.V. and Takii Seed for supporting the collecting missions and for their participation in regenerating the expedition materials.

\section{Compliance with ethical standards}

Conflict of interest The authors declare that the work described in this paper complies with ethical standards and that they have no conflict of interest.

Open Access This article is distributed under the terms of the Creative Commons Attribution 4.0 International License (http:// creativecommons.org/licenses/by/4.0/), which permits unrestricted use, distribution, and reproduction in any medium, provided you give appropriate credit to the original author(s) and the source, provide a link to the Creative Commons license, and indicate if changes were made.

\section{References}

Alercia A, Diulgheroff S, Mackay M (2015) FAO/Bioversity multi-crop passport descriptors V.2.1 [MCPD V.2.1]. Food and Agriculture Organization of the United Nations (FAO), Rome, Italy and Bioversity International, Rome

Andersen SB, Torp AM (2011) Spinacia. In: Kole C (ed) Wild crop relatives: genomic and breeding resources, vegetables. Springer, Berlin, pp 273-276

Castañeda-Álvarez NP, Khoury CK, Achicanoy HA, Bernau V, Dempewolf H, Eastwood RJ, Guarino L, Harker RH, Jarvis A, Maxted N, Müller JV, Ramirez-Villegas J, Sosa CC, Struik PC, Vincent H, Toll J (2016) Global conservation priorities for crop wild relatives. Nat Plants. https://doi.org/ 10.1038/nplants.2016.22

EU (2018) Sharing nature's genetic resources-ABS. European commission, http://ec.europa.eu/environment/nature/ biodiversity/international/abs/index_en.htm. Accessed 29 May 2019

FAO (2013) Genebank standards for plant genetic resources for food and agriculture. Food and Agriculture Organization of the United Nations, Rome

FAO (2018) International treaty on plant genetic resources for food and agriculture. Food and Agriculture Organization (FAO) of the United Nations, Rome. www.fao.org/planttreaty/areas-of-work/the-multilateral-system/the-smta/en/. Accessed 29 May 2019

FAOSTAT (2018) Statistics division of the Food and Agriculture Organization (FAO) of the United Nations, Rome. www.fao.org/faostat/. Accessed 3 May 2018

Finch-Savage WE, Leubner-Metzger G (2006) Seed dormancy and the control of germination. New Phytol 171(3):501-523

Fujito S, Takahata S, Suzuki R, Hoshino Y, Ohmido N, Onodera Y (2015) Evidence for a common origin of homomorphic and heteromorphic sex chromosomes in distinct Spinacia species. G3 Genes Genom Genet 5:1663-1673

Hajjar R, Hodgkin T (2007) The use of wild relatives in crop improvement: a survey of developments over the last 20 years. Euphytica 156:1-13

Handke S, Seehaus H, Radies M (2000) Detection of a linkage of the four dominant mildew resistance genes " $\mathrm{M}_{1} \mathrm{M}_{2} \mathrm{M}_{3} \mathrm{M}_{4}$ " in spinach from the wildtype Spinacia turkestanica. Gartenbauwissenschaft 65(2):73-78

Jarvis A, Lane A, Hijmans RJ (2008) The effect of climate change on crop wild relatives. Agric Ecosyst Environ 126:13-23

Khoury C, Laliberté B, Guarino L (2010) Trends in ex situ conservation of plant genetic resources: a review of global crop and regional conservation strategies. Genet Resour Crop Evol 57:625-639

Kik C (2008) Report of a Spinacia collecting expedition to Uzbekistan and Tajikistan. Iternary, collected material and data. CGN report 2008/12. CGN, Wageningen. http:// missions.cgn.wur.nl/NUT/NUT.htm. Accessed 29 May 2019

Kik C, Farzaliyev V, Mosulishvili M, Melyan G, Gabrielyan I (2011) Report of a Spinacia collecting mission to the Trans Caucasus. CGN report 21. CGN, Wageningen. http:// missions.cgn.wur.nl/NTC/NTC.htm. Accessed 29 May 2019

Maxted N, Avagyan A, Frese L, Iriondo JM, Magos BJ, Singer A, Kell SP (2015) ECPGR concept for in situ conservation of crop wild relatives in Europe. Wild Species Conservation in Genetic Reserves Working Group. European Cooperative Programme for Plant Genetic Resources, Rome

Morelock TE, Correll JC (2008) Spinach. In: Prohens J, Nuez F (eds) Vegetables I. Handbook of plant breeding, vol 1. Springer, New York, pp 189-218

Plantum (2018) Denomination of Pfs: 17, a new race of downy mildew in spinach. www.naktuinbouw.com/aboutnaktuinbouw/news/denomination-pfs-17-new-racedowny-mildew-spinach. Accessed 29 May 2019 
Sklensky DE, Davies PJ (2011) Resource partitioning to male and female flowers of Spinacia oleracea L. in relation to whole-plant monocarpic senescence. J Exp Bot 62(12):4323-4336

Sneep J (1982) The domestication of spinach and the breeding history of its varieties. Euphytica 13(Suppl. 2):1-27

Uotila P (1997) Spinacia. In: Reichinger KH (ed) Flora Iranica. Akademische Druck-und Verlagsanstalt, Graz, pp 59-63

Van de Wouw M, Kik C, van Hintum T, van Treuren R, Visser B (2010) Genetic erosion in crops: concept, research results and challenges. Plant Genet Resour Charact Util 8:1-15

Van Hintum TJL (2000) Duplication within and between germplasm collections. III. A quantitative model. Genet Resour Crop Evol 47:507-513

Van Treuren R, Coquin P, Lohwasser U (2012) Genetic resources collections of leafy vegetables (lettuce, spinach, chicory, artichoke, asparagus, lamb's lettuce, rhubarb and rocket salad): composition and gaps. Genet Resour Crop Evol 59:981-997

Van Treuren R, Hoekstra R, van Hintum TJL (2017) Inventory and prioritization for the conservation of crop wild relatives in The Netherlands under climate change. Biol Conserv 216:123-139

Xu C, Jiao C, Sun H, Cai X, Wang X, Ge C, Zheng Y, Liu W, Sun X, Xu Y, Deng J, Zhang Z, Huang S, Dai S, Mou B, Wang Q, Fei Z, Wang Q (2017) Draft genome of spinach and transcriptome diversity of 120 Spinacia accessions. Nat Commun 8:15275. https://doi.org/10.1038/ ncomms 15275

Publisher's Note Springer Nature remains neutral with regard to jurisdictional claims in published maps and institutional affiliations. 